\title{
Maternal use of baby walkers with young children: recent trends and possible alternatives
}

\author{
D DiLillo, A Damashek, L Peterson
}

\begin{abstract}
Objectives-To examine recent trends in baby walker and exersaucer use, and to assess maternal motivations for choosing to use or not use these devices with children.

Setting-Small, Midwestern city in the United States.

Methods-Retrospective telephone survey with a sample of 329 mothers who provided information about their use of walkers and exersaucers with 463 children born in Columbia, Missouri between January 1994 and April 1999.

Results-Baby walker use in the sample declined fairly steadily from 1994 to 1999 , whereas exersaucer use increased during the same period. Altogether $88 \%$ of mothers were aware of the injury risks associated with walkers, and this knowledge was the most commonly reported reason for abstaining from walker use. Remarkably, $38 \%$ of participants with knowledge of walker risks nevertheless used these devices. Participants reported many reasons for using walkers and exersaucers, including child entertainment, perceived developmental benefit, easy availability, and improved safety of exersaucers.

Conclusions-Public knowledge of the hazards of walkers seems to be high, and this awareness is a likely factor in many caregivers' decisions not to use them. Future interventions should focus particular attention on those caregivers who continue to use walkers despite knowledge of the associated risks. In addition to persuasive interventions, alternatives to walkers should be encouraged. Exersaucers represent one viable alternative, and should be promoted as such by the media, pediatricians, and other child care professionals.

(Injury Prevention 2001;7:223-227)
\end{abstract}

Department of Psychology, University of Nebraska-Lincoln

D DiLillo

Department of

Psychology, University of Missouri-Columbia A Damashek

L Peterson

Correspondence to: Dr David DiLillo,

Department of Psychology, University of

Nebraska-Lincoln, 238

Burnett Hall, Lincoln NE

68588-0308, USA

ddilillo@unl.edu every medically treated injury associated with walkers, 10 more occur that do not receive medical attention. ${ }^{2}$ In all, between $12 \%$ and $40 \%$ of children who use walkers experience an injury while in them..$^{2-6}$ Walkers are hazardous primarily because they permit preambulatory children nearly unlimited independent mobility. The most common walker related injuries involve falls down stairs, which may lead to head injuries such as skull fractures or concussions. ${ }^{378}$

In response to the clear risk of injury resulting from baby walkers, manufacturers began placing warning labels on them in $1995 .{ }^{9}$ Additionally, in 1998, the United States Consumer Products Safety Commission (CPSC) mandated that all new walkers be equipped with wider frames that do not fit through most doorways, as well as a gripping mechanism to serve as a brake when walkers begin to fall down stairs. Early indications, however, show that, while helpful, these changes may not be entirely effective in preventing serious injuries ${ }^{10}$; nor can these features reduce injury risk associated with walkers purchased before the new standards. Thus, in the absence of a complete ban, individual caregivers' decisions about whether to use walkers will remain a key determinant of walker related injuries.

The American Academy of Pediatrics and other child advocacy groups have endeavored to discourage walker use by publicizing the associated hazards. ${ }^{8911}$ Several researchers have also called for campaigns to reduce the use of walkers. ${ }^{12}$ It is currently unclear, however, to what extent the public is aware of the hazards associated with walkers, or whether this awareness is related to actual decreases in their use. Investigations over the past two decades have consistently found high rates of walker use, ranging from $53 \%$ to $92 \% .{ }^{2}{ }^{513-15}$ Unfortunately, due to variations in study design and the tendency to report only aggregated rates (that is, a single rate for all children in a study), it has been difficult to ascertain trends over time. Information about these patterns may, nevertheless, be helpful in determining whether public information campaigns are reaching target audiences and effectively discouraging walker use.

Injury researchers and the CPSC have encouraged the use of safe alternatives to walkers, which include stationary playstations, known generically as exersaucers. ${ }^{12}{ }^{16}$ Exersaucers resemble baby walkers, but have no wheels and are therefore presumed to be safer than walkers. Exersaucers also may provide many of the same benefits as walkers (for example, entertaining and occupying the child), representing a potentially appealing alternative. To 
our knowledge, however, no data presently exist concerning caregivers' perceptions of exersaucers or their preferences for using these newer devices rather than traditional mobile walkers.

To shed light on these and related questions, the following study was conducted with a community sample of mothers who gave birth to children during a recent six year period. Participants provided information concerning their reasons for walker and exersaucer use, as well as their knowledge of the dangers and other disadvantages associated with walkers. Mothers also reported about their use of walkers and exersaucers with each child in the family who had passed through walker use age. Data from these interviews should reveal avenues for the prevention of walker related injuries.

\section{Method}

RECRUITMENT PROCEDURES

All hospital births occurring in Columbia, Missouri (population 79 000) are published free of charge in the local newspaper, based upon information routinely provided to the newspaper by the city's two hospitals. Investigators used these newspaper reports to create a database containing the names, dates of birth, and phone numbers (when available) of all children born locally between January 1994 and April 1999 ( $n=2842)$. Participants were randomly recruited by phoning the families of every fifth child whose birth announcement was contained in the database. Only mothers of children at least 6 months of age (that is, old enough to use a walker) were contacted. The resulting sample was also stratified to reflect approximately the same proportion of births during each year in the community as a whole. Through these procedures, 294 mothers were reached by telephone, of which $264(89.8 \%)$ agreed to participate and completed the baby walker interview.

In addition to the 264 participants recruited by telephone, 65 mothers completed the baby walker interview in person (bringing the total sample to 329). These mothers, who also had children born between 1994 and 1999, were invited to complete the interview while participating in another injury project being conducted concurrently in our laboratory (see footnote at end of paper). All mothers asked to participate in the face-to-face interviews agreed to do so. Once these interviews were completed, participant names were deleted from the birth announcement database to avoid rerecruitment by telephone.

PARTICIPANTS

The 329 participating mothers were caregivers for a total of 463 children about whom they provided data for the present study. Of these children, 223 were female and 236 were male (four were missing gender data). Demographic comparisons between those interviewed by telephone and the 65 mothers recruited in person were made with a series of $t$ tests and $\chi^{2}$ values, and revealed no significant differences between the two groups with regard to race, education, occupational status, or socioeconomic status. The majority of all participants were white $(96 \%)$, with the remaining $4 \%$ being of various minority groups. Fewer than $1 \%$ of mothers had less than a seventh grade education, $1.5 \%$ graduated from junior high school, 12\% graduated from high school, $22.5 \%$ completed some college, $46.4 \%$ graduated from college, and $16.9 \%$ reported obtaining a graduate degree. The mean socioeconomic status of the sample, computed using the Hollingshead four factor index (Hollingshead AB. Four factor index of social status. Unpublished manuscript, Yale University 1975) was 48.98 (SD $=11.26$, range $17.5-$ 66.0 ). This suggests that a broad range of socioeconomic strata was represented, but that the average family was of an upper middle class.

INTERVIEWING PROCEDURES

The interview itself consisted of eight components assessing: (1) age and sex of all children in the home age 5 and younger; (2) whether a baby walker or exersaucer had been used with each child; (3) frequency of baby walker use; (4) reasons for using or not using baby walkers; (5) reasons for using exersaucers; (6) knowledge of walker risks; (7) where and when baby walker hazard information was acquired (if applicable); and (8) demographic information. To reduce potential reactivity to the questions about baby walkers, all questions were embedded within a larger interview about mothers' use of other baby furniture items, such as playpens and changing tables.

One clinical psychology graduate student and three psychology undergraduates conducted the interviews. Project coordinators trained interviewers until they were determined to be proficient. Training involved script rehearsal and the completion of several practice interviews that were audiotaped and evaluated before actual data collection. As noted, mothers recruited by birth announcements were contacted and interviewed by telephone; interviews with the remaining participants were conducted face-to-face. All procedures for this study received prior approval from the University of Missouri Institutional Review Board.

\section{Results}

BABY WALKER AND EXERSAUCER USE

Of the 329 mothers interviewed, $48.9 \%$ reported using baby walkers with at least one child in the family. Inquiries about walker use revealed that $45.6 \%$ of all children born during the six year time period had been placed in a walker on at least one occasion. The frequency of walker use varied among these children, with $14.1 \%$ having used a walker "once or twice", $16.5 \%$ "once in a while", $15.5 \%$ "a few times a month", $5.3 \%$ "on a weekly basis", and $48.5 \%$ daily.

Regarding exersaucers, $51.7 \%$ of mothers reported using them with at least one child in the family. Altogether $47.1 \%$ of all children in 
Table 1 Trends in baby walker and exersaucer use among children (1994-99)

\begin{tabular}{lllllll}
\hline Usage rates & $\begin{array}{l}1994 \\
(n=85)\end{array}$ & $\begin{array}{l}1995 \\
(n=76)\end{array}$ & $\begin{array}{l}1996 \\
(n=67)\end{array}$ & $\begin{array}{l}1997 \\
(n=90)\end{array}$ & $\begin{array}{l}1998 \\
(n=124)\end{array}$ & $\begin{array}{l}1999 \\
(n=19)\end{array}$ \\
\hline Baby walkers (\%) & 65.9 & 47.4 & 47.8 & 34.4 & 41.1 & 21.1 \\
Exersaucers (\%) & 19.0 & 34.2 & 55.2 & 62.2 & 58.5 & 52.6 \\
\hline
\end{tabular}

the sample had been placed in an exersaucer on at least one occasion. Frequency of use data for exersaucers were not obtained.

Table 1 depicts the percentage of children who were placed in walkers and exersaucers each year from 1994 to 1999 . Walker use rates declined from a high in 1994 of $65.9 \%$ to a low in 1999 of $21.1 \%$. Conversely, exersaucer use was lowest in $1994(19.0 \%)$ and highest in 1997 (62.2\%), with rates remaining at comparable levels for 1998 and 1999. Analysis of these patterns using Mantel-Haenszel $\chi^{2}$ tests revealed a significant downward trend for baby walker use $\left(\chi^{2}(1)=17.97, \mathrm{p}<0.001\right)$ from 1994 to 1999 , and a concomitant upward trend for exersaucer use $\left(\chi^{2}(1)=36.98, p<0.001\right)$ during the same six year time frame. A point-biserial correlation revealed a significant negative relationship between baby walker and exersaucer use across the six years $(r=-0.42$, $\mathrm{p}<0.001$ ), suggesting that caregivers tended to use either walkers or exersaucers with children.

KNOWLEDGE OF WALKER RISKS

At the time of the study $88.8 \%$ of all mothers reported having some knowledge of the hazards associated with baby walkers. When asked to name the sources from which they acquired this information, $72.9 \%$ cited print or broadcast media; $20.1 \%$ cited a child care professional (for example, a physician); $19.8 \%$ learned of the hazards from a friend or relative; $11.8 \%$ reported that a previous experience with an injury or near injury had taught them about the hazards; $8.6 \%$ cited common sense; $8.3 \%$ cited formal education; $3.8 \%$ cited walker warning labels; and $4.2 \%$ gave other sources.

Remarkably, $38.2 \%$ of mothers reported using walkers with one or more children, despite being aware of the associated risks at the time of use. To explore whether this trend was related to specific demographic characteristics, one way analyses of variance and $\chi^{2}$ tests were conducted on several variables. These analyses revealed no differences in socioeconomic status, ethnicity, or education between mothers who used walkers with knowledge of walkers hazards and those who used walkers but had no knowledge of the associated risks.

REASONS FOR WALKER AND EXERSAUCER USE All mothers who reported using walkers were asked about their motivations for doing so. In all, $48.3 \%$ cited perceived benefit to children (e.g., as a source of entertainment) as a factor in their decision to use walkers; $35.5 \%$ cited access (e.g., receiving one as a gift or having one left over from an older sibling); $29.4 \%$ believed that walkers fostered their child's development (e.g., to help children learn to walk); $21.8 \%$ reported parental convenience (e.g., to keep children occupied while the parent does housework); and $4.7 \%$ cited a perception that the home environment was safe for baby walker use (e.g., there are no stairs in the home).

Mothers who had never used walkers with their children also provided reasons for their decisions. Concern about safety issues (e.g., the child could fall down stairs) was by far the most common reason $(78.7 \%)$. The second most common reason was a conscious decision to use exersaucers instead of walkers $(10.8 \%)$. A lack of access to a walker and perceived detriment to children's motor development (e.g., damaging children's leg muscles) were cited by $8.8 \%$ and $8.0 \%$ of mothers, respectively.

Finally, all participants were asked to report advantages of (i.e., reasons for) exersaucer use. Safety concerns (e.g., exersaucers are safer than baby walkers) and child entertainment were cited as advantages of exersaucers by $64.4 \%$ and $44.3 \%$ of mothers respectively; $36.4 \%$ cited perceived benefit to child development (e.g., opportunity to exercise leg muscles), and $28.5 \%$ cited parental convenience (e.g., as a means to occupy the child while a parent does housework).

\section{Discussion}

To date, the primary strategies for discouraging walker use have been educational in nature, involving public awareness campaigns and the use of warning labels. Several investigations predating these campaigns showed little indication that parents perceived walkers to be dangerous. $^{2713}$ In contrast to these earlier studies, our finding that almost $89 \%$ of mothers were aware of walker hazards suggest that efforts to educate the public have been rather successful. It is also encouraging to note that $79 \%$ of mothers who did not use walkers specifically cited injury risk as the reason for their decision.

Despite these encouraging findings, $38 \%$ of those who reported having knowledge of walker dangers nevertheless decided to use these devices. This is consistent with other findings that many caregivers whose children are injured by walkers were aware of the dangers beforehand, and that a substantial proportion of these individuals continued walker use even after an injury. ${ }^{8}$ Thus, it appears that although risk information is sufficient to convince some caregivers to abstain from walker use, another segment of the population is not deterred from use by educational interventions, or even by the occurrence of an injury.

When asked about reasons for walker use, $22 \%$ of participants specifically cited caregiver convenience as a factor in their decision (e.g., "It frees me up to do housework" or "It's easier to supervise her while she's in the walker"). This figure is probably an underestimate given that those who cited other factors, such as child entertainment, may also perceive ease of supervision as a beneficial byproduct of walker use. Although it is easy to see why occupying a child in a walker could prove useful to a busy 
parent, the possibility that caregivers use walkers as a substitute for close supervision is concerning, for even the briefest lapse in supervision (e.g., answering the telephone or doorbell, glancing at the television) may be long enough for a mishap to occur. ${ }^{17}$

Our data indicate that walkers may be quite appealing to many caregivers. Most walker users reported several perceived advantages associated with using the devices. Walkers also tended to be relied on often, with nearly half $(48.5 \%)$ of these children using them daily. As suggested by prominent health behavior theories (e.g., the Heath Belief Model $^{18}{ }^{19}$ ), greater success in discouraging walker use might be achieved by providing caregivers with an alternative course of action that is both readily available and provides the same benefits as walkers. Our data showed that participants perceived many of the same reasons for use associated with both walkers and exersaucers. Furthermore, like mobile walkers, exersaucers are reasonably priced and are readily available alongside walkers in stores. For these reasons, exersaucers appear to represent an appealing, accessible, and presumably safe alternative to traditional walkers.

Regarding preferences for exersaucers versus walkers, the present study suggests that some parents may already be forgoing mobile walkers in favor of stationary playstations. Nearly two thirds of mothers who used exersaucers specifically cited safety issues as a factor motivating their decision. Our examination of the trends was certainly consistent with these individual reports. These analyses showed a significant inverse relationship between walker and exersaucer use for the period 1994 to 1999 . That is, the fairly steady decline in mobile walker use was mirrored by a concurrent upsurge in exersaucer use over the six year time period. Our correlational analysis also supported a significant negative relationship between walker and exersaucer use. It appears, then, that caregivers tend to use one or the other, but not both, devices with their children.

Limitations of this study should be noted. One potential problem concerns the limited data from children born during 1999, which suggested a decrease in walker use compared with previous years. This finding may be misleading due to the small number of participants from that year $(n=19)$, and the fact that some children had not completely passed through walker using age by the time of data collection. Less opportunity for these children to be exposed to walkers may have contributed to the lower rates for 1999. Second, although our sample contained participants with a range of characteristics on some demographic variables, the extent to which they represent the broader population of parents who may use baby walkers is unknown. A more diverse sample in terms of geographic location, ethnicity, and socioeconomic status could improve the generalizability of findings. Finally, as with all survey research, participant reports may have been affected by expectation biases.

\section{Key points}

- Awareness of baby walker hazards appears to be high among mothers.

- Hazard knowledge may be a factor in some caregivers' decisions not to use walkers.

- Nevertheless, many mothers with hazard knowledge persist in using walkers.

- Recent decreases in walker use and increases in the use of exersaucers suggest that stationary playstations are an appealing substitute for walkers.

- Prevention efforts should educate caregivers about walker risks, while also alerting them to possible alternatives such as exersaucers.

\section{Implications for prevention}

Results of this study have several implications for the prevention of walker related injuries. First, future interventions should target the sizable minority of caregivers who use walkers despite having knowledge of the associated risks. For these individuals, general risk knowledge appears insufficient to evoke a change in individual walker use. This type of "optimistic bias", involving an underestimation of personal risk, has been well documented in the adult literature and may pose a barrier to the discontinuance of walker use. ${ }^{20}{ }^{21}$ As suggested by the Health Belief Model, ${ }^{18}$ interventions should challenge individuals' perceptions of invulnerability to walker injuries by reinforcing the notion that even vigilant supervision does not guarantee protection against injury.

Ultimately, however, persuasive techniques alone may be insufficient to achieve maximum reductions in walker use. These approaches should be augmented with the presentation of practical and appealing alternatives to traditional walkers. The present data show trends in recent years away from walker use in favor of safer stationary playstations. Future interventions could capitalize upon these trends by actively promoting exersaucers. In the endand in the absence of a legislative ban on walkers-a twofold approach that addresses issues of personal vulnerability to walker injuries and informs caregivers of safe, accessible alternatives may prove to be the most fruitful prevention strategy.

\section{Footnote}

The other injury project focused on a broad range of parent-child interactions potentially related to unintentional injury. Although socially desirable responding on the part of these 65 participants cannot be ruled out, anonymous feedback obtained after the study indicated that mothers responded honestly and accurately to the interview questions. This is supported by the fact that many mothers readily reported placing children in walkers despite having knowledge of the associated risks.

This project was funded by a University of MissouriColumbia Research Council Grant while the first author was at the Department of Psychology, University of MissouriColumbia. No author has financial interests in or has been compensated by the companies that produce exersaucers. 1 Consumer Products Safety Commission. Baby walkers;
advance notice of proposed rulemaking; request for
comments and information. Federal Register
1994;59:39306-11.
2 Stoffman J, Bass M, Fox A. Head injuries related to the use
of baby walkers. Can Med Assoc $\mathcal{F} 1984 ; 131: 573-5$. 
3 Chiaviello C, Christoph R, Bond G. Infant walker-related injuries: a prospective study of severity and incidence. Pediinjuries: a prospective
atrics $1994 ; 93: 974-6$.

4 Mayr J, Gaisl M, Purtscher K, et al. Baby walkers-an underestimated hazard for our children? Eur $\mathcal{F}$ Pediat 1994;153:531-4.

5 Coury D, Kasten EF, Shepherd L, et al. Infant walker use in private practice populations. Am F Dis Child 1992;146:507.

6 American Medical Association Board of Trustees. Use of infant walkers. Am $\mathcal{F}$ Dis Child 1991;145:933-4.

7 Rieder M, Schwartz C, Newman J. Patterns of walker use and walker injury. Pediatrics 1986;78:488-93.

8 Smith G, Bowman M, Luria J, et al. Babywalker-related injuries continue despite warning labels and public education. Pediatrics 1997;100(2):e1.

9 American Academy of Pediatrics, Committee on Poison Prevention. Injuries associated with infant walkers. PediatPrevention. Injuries asso
rics 1995;95:778-80.

10 Ridenour MV. How effective are brakes on infant walkers? Percept Mot Skills 1997;84(3 pt 1):1051-7.

11 Marcella S, McDonald B. The infant walker: an unappreciated household hazard. Conn Med 1990;54:127-9.

12 Kendrick D, Marsh P. Babywalkers: prevalence of use and Kendrick D, Marsh P. Babywalkers: prevalence of use and
relationship with other safety practices. Inj Prev 1998;4: $295-8$
13 Fazen L, Felizberto P. Baby walker injuries. Pediatrics 1982; 70:106-9.

14 Kauffman IB, Ridenour M. Influence of an infant walker on onset and quality of walking pattern of locomotion: an electromyographic investigation. Percept Mot Skills 1977;45: 1323-9.

15 Kavanagh CA, Banco L. The infant walker: a previously unrecognized health hazard. Am $\mathcal{f}$ Dis Child 1982;136:2056.

16 Medford R. Babywalker-related injuries continue despite warning labels and public education. Pediatrics 1998;101: 1094-5.

17 Lang-Runtz H. Preventing accidents in the home. Can Med Assoc f 1983;129:482-5.

18 Janz N, Becker M. The health belief model: a decade later. Health Educ Q 1984;11:1-47.

9 Rosenstock I. Historical origins of the health belief model. Health Education Monographs 1974;2:328-35.

20 DeJoy DM. The optimism bias and traffic accident risk perception. Accid Anal Prev 1989;21:333-40.

21 Weinstein ND. Mindset, optimistic bias about personal risk and health-protective behaviour. Br $\mathcal{F}$ Health Psychol 1999; 4:289-300.

\section{6th World Conference on Injury Prevention and Control}

\section{2-15 May 2002, Montréal, Canada}

The Organizing Committee is very pleased to invite you to take part in the 6th World Conference on Injury Prevention and Control which will be held from May 12 to 15, 2002 at the Montréal Convention Centre. This meeting, on the theme of Injuries, Suicide and Violence: Building Knowledge, Policies and Practices to Promote a Safer World, will be an excellent opportunity for the participants to exchange information and forge links between sectors (health, transportation, safety, justice, etc) and, together, find new ways to improve the safety of populations and reduce the burden of injuries. The conference will deal first of all with safety problems in various contexts: on the road, in the workplace, in the home, and during recreational and sports activities, as well as the problems of suicide, violence, and post-trauma care. Each of these themes will be discussed extensively during the three days of the conference, which will include oral presentations, round tables, debates, and presentations on the most recent scientific advances.

In addition, cross disciplinary topics that are of interest to all the participants will be presented in plenary sessions to stimulate exchange between sectors and fields of specialty. Finally, satellite conferences, courses, site visits, and exhibits will complete the program. To ensure the quality of the scientific content of the conference, working groups bringing together leaders from each field have been established.

For the second time, this conference will take place in the Americas, which is why we are extending a very special invitation to our colleagues from Latin America. Montréal is a beautiful city, well known for its joie de vivre. It has a reputation for hospitality and safety, and also has a cultural heritage that is well worth discovering. We look forward to seeing you in Montréal in May 2002 at the 6th World Conference.

- Deadline for abstract submission: 15 September 2001.

- For registration, accommodation, and abstract submission forms and for more information, please consult the conference web site at http://www.trauma2002.com or contact the Conference Secretariat at +15148481133 (fax +1 514288 6469). 